\title{
Presencia y Expresión del Receptor ACE2 (Target de SARS-CoV-2) en Tejidos Humanos y Cavidad Oral. Posibles Rutas de Infección en Órganos Orales
}

\author{
Presence and Expression of ACE2 Receptor (Target of SARS-CoV-2) in Human \\ Tissues and Oral Cavity. Possible Routes Infection in Oral Organs
}

Gabriel Pastrian Soto

PASTRIAN, S. G. Presencia y expresión del receptor ACE2 (Target de SARS-CoV-2) en tejidos humanos y cavidad oral. Posibles rutas de infección en órganos orales. Int. J. Odontostomat., 14(4):501-507, 2020.

RESUMEN: Un nuevo coronavirus (SARS-CoV-2) ha sido reconocido como el agente etiológico de una misteriosa neumonía originada en Wuhan, China. La OMS ha nombrado a la nueva enfermedad como COVID-19 y, además, la ha declarado pandemia. Taxonómicamente, SARS-CoV-2 pertenece al género de los betacoronavirus junto con SARS-CoV y MERS-CoV. SARS-CoV-2 utiliza la enzima convertidora de la angiotensina 2 (ACE2) como el receptor objetivo para el ingreso en una célula huésped. La expresión de ACE2 en células de tejidos humanos podría indicar un potencial riesgo de reconocimiento por parte del virus y, por ende, ser susceptibles a la infección. Mediante algunas técnicas de laboratorio y de bioinformática, se ha visto una alta presencia de ACE2 en células epiteliales alveolares tipo II de pulmón y en enterocitos del intestino delgado. En la cavidad oral, se ha podido identificar la presencia de ACE2, principalmente, en células epiteliales de glándulas salivales y células epiteliales de la lengua. Además, se ha reportado la manifestación de algunos síntomas, como sequedad bucal y ambligeustia, los que podrían estar relacionadas con una infección de SARS-CoV-2 en estos órganos. Sin embargo, son necesarios mayores estudios que evidencien esta situación.

PALABRAS CLAVE: COVID-19, SARS-CoV-2, ACE2, cavidad oral, infección.

\section{INTRODUCCIÓN}

Una misteriosa neumonía de etiología desconocida comenzó a informarse por primera vez hacia finales de diciembre de 2019 en la ciudad de Wuhan, China. Científicos chinos lograron aislar el código genético del patógeno responsable de la enfermedad estableciéndolo como un nuevo coronavirus (Chen et al., 2020a). Posteriormente, el 11 de febrero de 2020, la Organización Mundial de la Salud (OMS) nombró a esta nueva enfermedad como COVID-19 (Peng et al., 2020) y, además, de acuerdo con los análisis filogenéticos y taxonómicos, el comité internacional de taxonomía de virus (ICTV) sugirió el nombre del nuevo coronavirus como "síndrome respiratorio agudo severo por coronavirus 2" (SARS-CoV-2) (Li et al., 2020). La enfermedad por COVID-19 se ha extendido rápidamente en muchos países. El 11 de marzo de 2020, COVID-19 fue declarada pandemia por la OMS y, hasta el momento, se han acumulado millones de casos confirmados a nivel mundial (Zou et al., 2020). Al día 21 de mayo de 2020, La OMS ha reportado un total de 4.893.186 casos confirmados y un total de 323.256 fallecidos (World Health Organization, 2020).

Los coronavirus pertenecen a la familia Coronaviridae del orden Nidovirales. Actualmente, existen cuatro géneros reconocidos, correspondientes a alfacoronavirus, betacoronavirus, gammacoronavirus y deltacoronavirus (Rabi et al., 2020; Peng et al.). Taxonómicamente, SARS-CoV-2 pertenece al género de los betacoronavirus, los cuales, infectan principalmente al sistema nervioso central, respiratorio y gastrointestinal de humanos y mamíferos (Peng et al.). La mayoría de los coronavirus que infectan a los humanos causan enfermedades respiratorias leves, sin embargo, algunos de ellos han causado enfermeda- 
des respiratorias graves e incluso fatales. Estos coronavirus corresponden al Síndrome Respiratorio Agudo Severo (SARS-CoV) y al Síndrome Respiratorio Medio Oriente (MERS-CoV), los que fueron identificados en el año 2002 y 2012 respectivamente (Han et al., 2020; Peng et al.). Existe una relación de patogenicidad entre SARS-CoV y SARS-CoV-2. Los principales síntomas definidos en SARS-CoV-2 incluyen fiebre, tos seca, mialgia, fatiga y dificultad respiratoria; y en menor medida, diarrea, naúseas y vómitos (Ozma et al., 2020), síntomas similares a los causados por SARS-CoV (Wan et al., 2020). La similitud genética en la secuencia de nucleótidos entre ambos virus corresponde aproximadamente a un 79 \% (Peng et al.) y, además, ambos reconocen al mismo receptor de entrada para infectar a una célula huésped (Ren et al., 2020).

Genéticamente, SARS-CoV-2 está formado por una cadena única de RNA monocatenario de polaridad positiva (+ssRNA) (Wong et al., 2020) y, morfológicamente, por una nucleocápside (donde se protege su material genético) y por una cubierta o envoltura externa dispuesta por proteínas estructurales principales ( $S, M$ y E) y proteínas accesorias (Mousavizadeh \& Ghasemi, 2020; Rabaan et al., 2020)

\section{Reconocimiento de la Célula Huésped y Mecanis- mo de Entrada de SARS-CoV-2}

La entrada de todos los coronavirus en las células hospederas está mediada por la proteína estructural principal Spike (Proteína S), proteína que les da la apariencia de una corona solar (Chen et al., 2020a). En el caso de los coronavirus relacionados con el SARS, la proteína $S$ contiene lo que se denomina el dominio de unión al receptor (RBD). EI RBD, reconoce y se une específicamente a un receptor presente en las células diana (Rabi et al.; Wan et al.; Ren et al.). En el virus SARS-CoV, se identificó a la enzima convertidora de la angiotensina 2 (ACE2) como el receptor necesario para la entrada viral, siendo este receptor, vital para la infección (Ren et al.; Li et al.). Al igual que SARS-CoV, SARS-CoV-2 utiliza el mismo receptor ACE2 para ingresar e infectar una célula huésped. Esta característica se debe a la gran similitud en las relaciones filogenéticas y genómicas entre ambos coronavirus (Mousavizadeh \& Ghasemi). La secuencia genética que codifica para la proteína S de SARSCoV-2 y de SARS-CoV, tiene una similitud de alrededor de un $78 \%$, y para el dominio RBD, una similitud de un 76 \% (Wan et al.; Chen et al., 2020a; Wong et al.; Xu et al., 2020a).
La proteína S de SARS-CoV-2 posee dos subunidades, S1 y S2. En la subunidad S1 se localiza el dominio RBD, el cual, permite el reconocimiento y la unión al receptor específico de la célula huésped, mientras que, la subunidad S2 permite la fusión de la membrana viral con la membrana celular (Chen et al., 2020a; Guo et al., 2020; Xu et al., 2020a; Rabaan et al.). Después de la exitosa unión de la proteína de $S$ al receptor ACE2, esta es procesada proteolíticamente por una serina proteasa de transmembrana de tipo II (TMPRSS2) (Rabi et al.; Rabaan et al.; Vinayachandran \& Balasubramanian, 2020). TMPRSS2 produce una escisión en dos diferentes posiciones del dominio S2, lo que permite, la separación del dominio RBD, la activación de la proteína $S$ y la posterior fusión de ambas membranas (Rabaan et al.). De esta manera, la partícula vírica ingresa en la célula huésped y se produce la liberación de su material genético en el citoplasma de la célula infectada (Chen et al., 2020a; Guo et al.; Xu et al., 2020a; Rabaan et al.). Se ha sugerido que las células en las que ACE2 y TMPRSS2 están presentes simultáneamente, son más susceptibles a la entrada de SARS-CoV-2 (Rabi et al.).

El grado de afinidad que resulta de la unión entre el dominio RBD de la proteína $S$ y el receptor ACE2, determina la eficiencia de ingreso del virus en la célula hospedera (Wan et al.). Se ha demostrado que el dominio RBD de SARS-CoV-2 se une con una alta afinidad al receptor ACE2, lo que se correlaciona con su eficiente propagación entre los humanos (Wong et al.). Estudios en criomicroscopía electrónica (Cryo-EM) demostraron que SARS-CoV-2 tenía una afinidad diez veces mayor a ACE2 en comparación con SARS-CoV, lo que es consistente con su mayor eficiencia de infección. Estos hallazgos indican que el receptor ACE2 podría ser crucial para la infección, progresión y pronóstico de COVID-19 (Li et al.; Guo et al.; D'Amico et al., 2020).

\section{ACE2 y Su Rol en la Fisiología Cardiovascular}

ACE2 es una aminopeptidasa asociada a la membrana expresada en diferentes tejidos (Jia et al., 2005, 2006). Fue descubierta en el año 2000 como un homólogo de la enzima convertidora de la angiotensina (ECA) (Harmer et al., 2002). Se ha visto que posee una potente acción reguladora negativa del sistema reninaangiotensina (RAS), contribuyendo así, a la mantención de la homeostasis del sistema (Li et al.).

EI RAS, juega un papel importante en la fisiología cardiovascular y en la homeostasis a través 


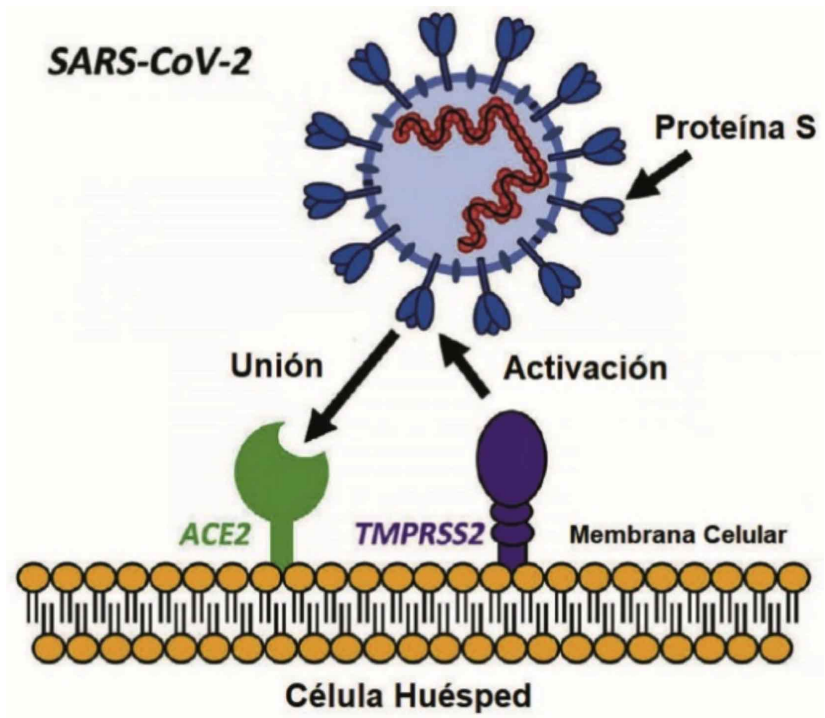

Fig 1. Reconocimiento de ACE2 y mecanismo de entrada de SARS-CoV-2. La proteína S reconoce y se une al receptor ACE2 por medio del dominio RBD. Posteriormente, la proteína de S es procesada proteolíticamente por TMPRSS2 produciéndose la separación del dominio RBD, la activación de la proteína $S$ y la posterior fusión de ambas membranas (Adaptado de Mousavizadeh \& Ghasemi).

de la regulación del equilibrio electrolítico, la presión arterial y el tono vascular (Verma et al., 2019; Li et al.). La ECA cataliza la formación de angiotensina II (Ang II) a partir de angiotensina I, desempeñando un papel clave en el control de la función cardiorenal y en el control de la presión arterial (Harmer et al.). La Ang II es un potente vasoconstrictor ( $\mathrm{Li}$ et al.). Una disfunción del RAS resulta en concentraciones elevadas de Ang II, lo que contribuye al aumento del estrés oxidativo, la inflamación y, además, al desarrollo de síndrome metabólico, diabetes y sus complicaciones asociadas, como retinopatía diabética (Verma et al.). La homeostasis del RAS es crítica para la regulación fisiológica y patológica de varios órganos, incluidos el corazón, los riñones y los pulmones (Li et al.). Los inhibidores específicos de Ang II son una de las clases de medicamentos más ampliamente recetados en cardiología y son utilizados en el tratamiento de la hipertensión y de la insuficiencia cardíaca (Harmer et al.).

En el RAS, ACE2 cataliza la formación de angiotensina (1-7) (Ang 1-7) a partir de Ang II, lo que permite la reducción de la inflamación y del estrés oxidativo estimulado por Ang II, ya que, Ang 1-7 posee efectos opuestos a Ang II, tales como, vasodilatación, efecto anti-inflamatorio y efecto anti- proliferativo (Verma et al.; Li et al.; Harmer et al.). Además, ACE2 regula los cambios patológicos locales de varios órganos, incluidos el corazón, los riñones y los pulmones ( $\mathrm{Li}$ et al.). Por lo que, ACE2 tiene un efecto protector en enfermedades cardiovasculares y metabólicas, como la diabetes (Verma et al.).

\section{Presencia y Localización de ACE2 en Tejidos Hu- manos}

La expresión y distribución de ACE2 en el cuerpo humano puede indicar las potenciales rutas de infección de SARS-CoV-2. Las células que expresan ACE2 pueden actuar como objetivos virales susceptibles de ser infectadas por la enfermedad de COVID19 (Xu et al., 2020a).

Un estudio que evaluó el perfil transcripcional total de expresión de RNA mensajero (mRNA) para ACE2 en 72 tejidos humanos mediante qRT-PCR, encontró que la presencia de ACE2 estaba altamente expresada en testículos, tejidos renales, cardiovasculares y, de manera especial, en tejidos gastrointestinales, incluyendo íleon, duodeno, yeyuno, ciego y colon, siendo en el íleon la expresión más alta en comparación con todos los 72 tejidos evaluados (Harmer et al.). Hamming et al. (2004) Investigaron, mediante inmunohistoquímica, la localización de ACE2 en varios órganos humanos (mucosa oral y nasal, nasofaringe, pulmón, estómago, intestino delgado, colon, piel, ganglios linfáticos, timo, médula ósea, bazo, hígado, riñón y cerebro), hallando una abundante y marcada tinción por ACE2 en células epiteliales alveolares tipo I y II de pulmón y en enterocitos de todo el intestino delgado, es decir, duodeno, yeyuno e íleon. Además, encontraron una destacable presencia, en todos los órganos estudiados, de ACE2 en células endoteliales de pequeños y grandes vasos arteriales y venosos, al igual que, en células del músculo liso de arterias. A través de un análisis bioinformático de técnicas de secuenciación de RNA unicelular (single-cell RNASeq o scRNA-Seq) y de transcriptomas unicelulares obtenidos de bases de datos públicas, se estudió el perfil de expresión de RNA relacionado con ACE2, donde se identificó, una alta expresión de ACE2 en células epiteliales alveolares tipo II de pulmón, células epiteliales estratificadas del esófago superior, enterocitos del íleon y colon, colangiocitos del tracto biliar, células miocárdicas, células del túbulo proximal del riñón y células uroteliales de la vejiga (Xu et al., 2020a; D'Amico et al.). 
Estos hallazgos indican que tanto la expresión de mRNA como la presencia de ACE2 se encuentra altamente manifestada en tejidos renales, cardiovasculares, gastrointestinales y pulmonares (Hamming et al.), lo que concuerda con el papel desempeñado por ACE2 en el control de la función cardiorenal y en el control la presión arterial (Harmer et al.). Sin embargo, estos tejidos deben considerarse con un alto riesgo potencial de infección por SARS-CoV-2 (Xu et al., 2020a).

\section{Presencia y Localización de ACE2 en la Cavidad Oral}

La mayoría de los estudios previamente expuestos no consideraron tejidos de la cavidad oral para detectar presencia o expresión de ACE2. El estudio que evaluó el perfil transcripcional total de mRNA de ACE2 en 72 tejidos humanos no se consideró tejidos orales (Harmer et al.). No obstante, existen estudios que sí reportan la presencia de ACE2 en la cavidad oral, aunque, estos son muy limitados. En estos, se evidencia presencia de ACE2 en células de glándulas salívales y en células de la mucosa oral (Xu et al., 2020a,b; Wang et al., 2020).

\section{Presencia de ACE2 en Glándulas Salivales}

Para identificar la posible ruta de infección en el virus SARS-CoV, Liu et al., (2011) investigaron, por medio de inmunohistoquímica, la localización y distribución de ACE2 en células de todo el tracto respiratorio en monos macacos Rhesus, incluyendo cavidad nasal, nasofaringe, orofaringe, epiglotis, laringe, tráquea, bronquios y pulmones. Describieron que, al igual que en tejidos humanos, numerosas células que recubren el tracto respiratorio de estos animales fueron positivas a ACE2, y en especial, células morfológicamente compatibles con epitelio ductal de glándulas salivales. Chen et al., (2020b) analizaron los perfiles transcripcionales en masa de RNA (bulk RNA-Seq) para ACE2 en cuatro bases públicas de datos (GTEx, HPA, FANTOM5 y Consensus) donde encontraron que, a pesar de que ACE2 está altamente expresado en el sistema gastrointestinal, testículos, riñones y músculos del corazón, también se expresa en glándulas salivales, aunque en un nivel relativamente menor. Wang et al. observaron que, según la base de datos publica GTEx, ACE2 puede ser detectada en glándulas salivales con un nivel medio de expresión de 1.8 pTPM (transcritos de codificación de proteínas por millón), ocupando el décimo lugar entre todos los órganos del organismo.

\section{Presencia de ACE 2 en la Mucosa Oral}

Hamming et al. hallaron, por tinción de inmunohistoquímica, presencia ACE2 en la capa basal del epitelio escamoso no queratinizado de la mucosa nasal, oral y de la nasofaringe. A fin de explorar y validar la expresión de ACE2 en la mucosa oral, Xu et al. (2020a) analizaron la expresión, composición y proporción de expresión de ACE2 en diferentes células de tejidos de la cavidad oral mediante perfiles transcripcionales bulk RNA-Seq de dos bases de datos públicas (TCGA y FANTOM5) y mediante un estudio independiente de scRNA-seq en cuatro tejidos de la mucosa oral (dos en el del dorso de la lengua y dos en la mucosa bucal y gingival). De acuerdo con sus resultados, existió expresión general de ACE2 en células epiteliales de la mucosa oral, siendo altamente manifestada en células epiteliales de la lengua.

\section{Posibilidad de Infección por SARS-CoV-2 en la Ca- vidad Oral y Sintomatología Asociada}

Se ha demostrado que células epiteliales de glándulas salivales y de la mucosa oral expresan el receptor ACE2 y teóricamente podrían ser sitios de infección por SARS-CoV-2 (Chen et al., 2020b; Wang et al.; Xu et al., 2020b). Sin embargo, limitados estudios explican cómo se daría este proceso infectivo y que síntomas podrían manifestarse asociados a la enfermedad COVID-19 en la cavidad oral (Peng et al.).

Liu et al. proponen que la infección por SARSCoV-2 en las glándulas salivales correspondería a una de las primeras etapas de infección en el organismo. En esta etapa inicial, Vinayachandran \& Balasubramanian consideran la posibilidad de que las glándulas salivales actúen como un reservorio del virus, albergando así, una infección latente que podría reactivarse posteriormente. Esta situación, podría ser la razón detrás de la transmisión de la infección entre casos asintomáticos, ya que, el virus se encontraría contenido en las células de las glándulas y todavía no progresando hacia las vías respiratorias. Una alta expresión de ACE2 en las células epiteliales de la mucosa oral, sobre todo, en células epiteliales de la lengua, proporciona posibles vías de entrada para SARS-CoV2. Esta situación determina la posibilidad de que se manifiesten síntomas orales, los cuales, podrían considerarse como síntomas iniciales de la infección por COVID-19. Sin embargo, Hamming et al. estiman que estas células no deberían considerarse como un sitio primario de entrada para la infección, ya que, a partir de sus estudios, la localización de ACE2 en la capa 
basal y no en la superficie de las células epiteliales de la mucosa oral, nasal y de la nasofaringe, no permitiría un contacto directo de las partículas víricas con el receptor.

Respecto a los síntomas que podrían manifestarse en la cavidad oral. Chen et al. (2020b) elaboraron un cuestionario sobre el estado de salud bucal en 108 pacientes confirmados con COVID-19 para indagar la manifestación de 14 síntomas. Del análisis de este cuestionario, aproximadamente la mitad de los pacientes encuestados manifestaron principalmente 2 síntomas, correspondientes a sequedad de bucal y a ambligeustia. Wang et al. afirman que una infección por SARS-CoV-2 en las glándulas salivales podría traducirse en una sialoadenitis tanto aguda como crónica. Para una sialoadenitis aguda, los investigadores sugieren que, al unirse el virus a los receptores ACE2 de las células epiteliales de las glándulas salivales, posteriormente, ingresar en ellas, replicarse y finalmente, lisarlas al momento de su salida, provocaría la manifestación de algunos signos y síntomas propios de una inflamación, tales como, molestias, hinchazón y dolor, de manera particular, en las glándulas salivales mayores (parótidas y submandibulares). En el caso de una sialoadenitis crónica, una persistente destrucción por causa inflamatoria de las glándulas salivales provocaría una reparación mediante proliferación de fibroblastos y la formación de tejido conectivo fibroso donde, además, se produciría una hiposecreción salival causada principalmente por la reparación fibrosa de las células acinares.

\section{DISCUSIÓN}

Se ha reconocido a ACE2 como el receptor de unión de SARS-CoV-2 en el inicio del proceso infeccioso en una célula huésped. Esta unión se logra mediante el reconocimiento del dominio RBD perteneciente a la subunidad S1 de la proteína S viral. La distribución y presencia de ACE2 en los tejidos del cuerpo humano podrían actuar como potenciales objetivos virales y, por lo tanto, ser susceptibles a la infección.

Mediante técnicas de laboratorio como qRTPCR, inmunohistoquímica y de bioinformática (scRNASeq y bulk RNA-Seq), se ha investigado la distribución, expresión y presencia de ACE2 en diferentes tejidos del cuerpo humano, correspondiendo a una alta presencia en tejidos de sistemas renales, cardiovasculares, gastrointestinales y pulmonares, específicamente, en células epiteliales alveolares tipo II de pulmón y en enterocitos del intestino delgado. La mayor presencia de ACE2 en estos tejidos se condice con los principales síntomas de la enfermedad por COVID-19, las que incluyen fiebre, tos seca, mialgia, fatiga y dificultad respiratoria; y en menor medida, diarrea, náuseas y vómitos. Esta situación da cuenta del alto riesgo potencial que tienen estos tejidos de ser infectados por SARS-CoV-2. En la cavidad oral, por medio de las mismas técnicas anteriormente enunciadas, se ha podido identificar la presencia de ACE2, principalmente, en células epiteliales de glándulas salivales y en células epiteliales de la lengua. Estos hallazgos indican que la cavidad oral también puede tener una susceptibilidad a la infección por COVID19. Estudios sugieren que esta infección podría corresponder a una las primeras etapas de la infección viral en el organismo, donde incluso, las glándulas salivales podrían ser un reservorio del virus en periodos asintomáticos. Además, se han reportado algunos síntomas relacionados con la enfermedad, tales como, sequedad bucal y ambligeustia, en el cual, se estima que estos síntomas se producirían debido a una disfunción de la lengua y de las glándulas salivales al estar infectadas por el virus, sin embargo, no existe evidencia histopatológica que respalde una invasión directa de SARS-CoV-2 en estos tejidos. Igualmente, se propone que pacientes que posean una infección viral en las glándulas salivales podrían llegar a sufrir de sialoadenitis aguda y crónica.

Por lo tanto, se debe prestar más atención a estructuras de la cavidad oral, especialmente, las glándulas salivales y la lengua, ya que, estos pueden ser objetivos iniciales de infección por SARS-CoV-2. Esto es debido a que algunas de las células de estos órganos expresan el receptor ACE2 y, por lo tanto, podrían servir de unión a las partículas víricas para iniciar un ciclo de infección. El identificar algunos de los síntomas asociados a la enfermedad podría proporcionar un modo más de prevención en la práctica clínica dental ante la posibilidad de enfrentar un paciente potencialmente contagiado. De todas maneras, son necesarios mayores estudios que evidencien la posibilidad real de infección por COVID-19 en la cavidad oral, junto con determinar las características del proceso infectivo $y$, a su vez, establecer de manera más clara la sintomatología asociada a la infección.

AGRADECIMIENTOS. Escuela de Odontología. Facultad de Ciencias de la Universidad Mayor, sede Santiago. Chile. 
PASTRIAN, S. G. Presence and expression of ACE2 receptor (Target of SARS-CoV-2) in human tissues and oral cavity. Possible routes infection in oral organs. Int. J. Odontostomat., 14(4):501-507, 2020.

A novel coronavirus (SARS-CoV-2) has been recognized as a etiologic agent of a mysterious pneumonia originating in Wuhan, China. WHO has named the new disease as COVID-19 and, in addition, has declared it a pandemic. Taxonomically, SARS-CoV2 belongs to the betacoronavirus genus along with SARS-CoV and MERS-CoV. SARS-CoV-2 uses angiotensin-converting enzyme 2 (ACE2) as the target receptor for entry into a host cell. The expression of ACE2 in cells of human tissues could indicate a potential risk of recognition by the virus and, therefore, be susceptible to infection. Through some laboratory and bioinformatics techniques, high presence of ACE2 has been seen in type II alveolar epithelial cells of the lung and enterocytes of the small intestine. In oral cavity, mainly presence of ACE2 has been identified in epithelial cells of salivary glands and epithelial cells of tongue. In addition, manifestation of some symptoms, such as dry mouth and amblygeustia, have been reported, which could be related to a SARS-CoV-2 infection in these organs. However, further studies are needed to prove this situation.

KEY WORDS: COVID-19, SARS-CoV-2, ACE2, oral cavity, infection.

\section{REFERENCIAS BIBLIOGRÁFICAS}

Chen, L.; Zhao, J.; Peng, J.; Li, X.; Deng, X.; Geng, Z.; Shen, Z.; Guo, F.; Zhang, Q.; Jin, Y.; et al. Detection of 2019-nCoV in saliva and characterization of oral symptoms in COVID-19 patients. SSRN, 2020b. DOI: https://www.doi.org/10.2139/ ssrn. 3557140

Chen, Y.; Guo, Y.; Pan, Y. \& Zhao, Z. J. Structure analysis of the receptor binding of 2019-nCoV. Biochem. Biophys. Res. Commun., 525:(1):135-40, 2020a. DOI: https://www.doi.org/ 10.1016/j.bbrc.2020.02.071

D'Amico, F.; Baumgart, D. C.; Danese, S. \& Peyrin-Biroulet, L. Diarrhea during COVID-19 infection: pathogenesis, epidemiology, prevention, and management. Clin. Gastroenterol. Hepatol., 2020. DOI: https://www.doi.org/ 10.1016/ j.cgh.2020.04.001

Guo, Y. R.; Cao, Q. D.; Hong, Z. S.; Tan, Y. Y.; Chen, S. D.; Jin, H. J.; Tan, K. S.; Wang, D. Y. \& Yan, Y. The origin, transmission and clinical therapies on Coronavirus Disease 2019 (COVID19) outbreak - An update on the status. Mil. Med. Res., 7(1):11, 2020.

Hamming, I.; Timens, W.; Bulthuis, M.; Lely, A.; Navis, G. \& Van Goor, $\mathrm{H}$. Tissue Distribution of ACE2 protein, the functional receptor for SARS coronavirus. A first step in understanding SARS pathogenesis. J. Pathol., 203(2):631-7, 2004.
Han, Q.; Lin, Q.; Jin, S. \& You, L. Coronavirus 2019-nCoV: A brief perspective from the front line. J. Infect., 80(4):373-7, 2020.

Harmer, D.; Gilbert, M.; Borman, R. \& Clark, K. L. Quantitative mRNA expression profiling of ACE 2, a novel homologue of angiotensin converting enzyme. FEBS Lett., 532(1-2):10710, 2002.

Jia, H. P.; Look, D. C.; Hickey, M.; Shi, L.; Pewe, L.; Netland, J.; Farzan, M.; Wohlford-Lenane, C.; Perlman, S. \& McCray Jr., P. B. Infection of human airway epithelia by SARS coronavirus is associated with ACE2 expression and localization. Adv. Exp. Med. Biol., 581:479-84, 2006.

Jia, H. P.; Look, D. C.; Shi, L.; Hickey, M.; Pewe, L.; Netland, J.; Farzan, M.; Wohlford-Lenane, C.; Perlman, S. \& McCray Jr., P. B. ACE2 receptor expression and severe acute respiratory syndrome coronavirus infection depend on differentiation of human airway epithelia. J. Virol., 79(23):14614-21, 2005.

Li, Y.; Zhou, W.; Yang, L. \& You, R. Physiological and pathological regulation of ACE2, the SARS-CoV-2 receptor. Pharmacol. Res., 157:104833, 2020.

Liu, L.; Wei, Q.; Alvarez, X.; Wang, H.; Du, Y.; Zhu, H.; Jiang, H.; Zhou, J.; Lam, P.; Zhang, L.; et al. Epithelial cells lining salivary gland ducts are early target cells of severe acute respiratory syndrome coronavirus infection in the upper respiratory tracts of rhesus macaques. J. Virol., 85(8):4025-30, 2011.

Mousavizadeh, L. \& Ghasemi, S. Genotype and phenotype of COVID-19: Their roles in pathogenesis. J. Microbiol. Immunol. Infect., 2020. DOI: https://www.doi.org/10.1016/ j.jmii.2020.03.022

Ozma, M. A.; Maroufi, P.; Khodadadi, E.; Köse, S..; Esposito, I.; Ganbarov, K.; Dao, S.; Esposito, S.; Dal, T.; Zeinalzadeh, E.; et al. Clinical manifestation, diagnosis, prevention and control of SARS-CoV-2 (COVID-19) during the outbreak period. Infez. Med., 28(2):153-65, 2020.

Peng, X.; Xu, X.; Li, Y.; Cheng, L.; Zhou, X. \& Ren, B. Transmission routes of 2019-nCoV and controls in dental practice. Int. J. Oral Sci., 12(1):9, 2020

Rabaan, A. A.; Al-Ahmed, S. H.; Haque, S.; Sah, R.; Tiwari, R.; Malik, Y. S.; Dhama, K.; Yatoo, M. I.; Bonilla-Aldana, D. K. \& Rodriguez-Morales, A. J. SARS-CoV-2, SARS-CoV, and MERS-COV: a comparative overview. Infez. Med., 28(2):17484, 2020.

Rabi, A. F.; Al Zoubi, M. S.; Kasasbeh, G. A.; Salameh, D. M. \& Al-Nasser, A. D. SARS-CoV-2 and coronavirus disease 2019: what we know so far. Pathogens, 9(3):231, 2020.

Ren, X.; Glende, J.; Al-Falah, M.; de Vries, V.; SchwegmannWessels, C.; Qu, X.; Tan, L.; Tschernig, T.; Deng, H.; Naim, $H$. Y.; et al. Analysis of ACE2 in polarized epithelial cells: surface expression and function as receptor for severe acute respiratory syndrome-associated coronavirus. J. Gen. Virol., 87(Pt. 6):1691-5, 2006

Verma, A.; Xu, K.; Du, T.; Zhu, P.; Liang, Z.; Liao, S.; Zhang, J.; Raizada, M. K.; Grant, M. B. \& Li, Q. Expression of human ACE2 in lactobacillus and beneficial effects in diabetic retinopathy in mice. Mol. Ther. Methods Clin. Dev., 14:16170, 2019.

Vinayachandran, D. \& Balasubramanian, S. Salivary diagnostics in COVID-19: Future research implications. J. Dent. Sci., 2020. DOI: https://www.doi.org/10.1016/j.jds.2020.04.006

Wan, Y.; Shang, J.; Graham, R.; Baric, R. S. \& Li, F. Receptor recognition by the novel coronavirus from wuhan: an analysis based on decade-long structural studies of SARS coronavirus. J. Virol.,94:(7):e00127-20, 2020.

Wang, C.; Wu, H.; Ding, X.; Ji, H.; Jiao, P.; Song, H.; Li, S. \& Du, H. Does infection of 2019 novel coronavirus cause acute and/ or chronic sialadenitis? Med. Hypotheses, 140:109789, 2020. 
PASTRIAN, S. G. Presencia y expresión del receptor ACE2 (Target de SARS-CoV-2) en tejidos humanos y cavidad oral. Posibles rutas de infección en órganos orales. Int. J. Odontostomat., 14(4):501-507, 2020.

Wong, S.; Lui, R. N. S. \& Sung, J. J. Y. Covid-19 and the digestive system. J. Gastroenterol. Hepatol., 35(5):744-8, 2020.

World Health Organization (WHO). Coronavirus Disease 2019 (COVID-19) Situation Report - 122. Ginebra, World Health Organization, 2020. Disponible en: https://www.who.int/docs/ default-source/coronaviruse/situation-reports/20200521covid- 19-sitrep-122.pdf?sfvrsn=24f20e05_2

Xu, H.; Zhong, L.; Deng, J.; Peng, J.; Dan, H.; Zeng, X.; Li, T. \& Chen, Q. High expression of ACE2 receptor of 2019-nCoV on the epithelial cells of oral mucosa. Int. J. Oral Sci., 12:8, 2020a.

Xu, R.; Cui, B.; Duan, X.; Zhang, P.; Zhou, X. \& Yuan, Q. Saliva: potential diagnostic value and transmission of 2019-nCoV. Int. J. Oral. Sci., 12(1):11, 2020 b.

Zou, X.; Chen, K.; Zou, J.; Han, P.; Hao, J. \& Han, Z. Single-cell RNA-seq data analysis on the receptor ACE2 expression reveals the potential risk of different human organs vulnerable to 2019-nCoV infection. Front. Med., 14(2):185-92, 2020.
Dirección para correspondencia:

Dr. Gabriel Pastrian Soto

Edificio Cobija

Cobija 2191 oficina 404-A

Calama

CHILE

Email: gabriel.pastrians1@mayor.cl

Recibido : 21-05-2020

Aceptado: 26-05-2020 